\title{
Role of alveolar macrophages in chronic obstructive pulmonary disease
}

\section{Ross Vlahos ${ }^{*}$ and Steven Bozinovski ${ }^{*}$}

Department of Pharmacology and Therapeutics, Lung Health Research Centre, The University of Melbourne, Parkville, VIC, Australia

Edited by:

Klaus Ley, La Jolla Institute for Allergy and Immunology, USA

\section{Reviewed by:}

Andrew Tasman Hutchinson,

University of Technology Sydney, Australia

Janos G. Filep, University of

Montreal, Canada

\section{${ }^{*}$ Correspondence:}

Ross Vlahos and Steven Bozinovski,

Department of Pharmacology and

Therapeutics, Lung Health Research

Centre, The University of Melbourne,

Parkville, VIC 3010, Australia

e-mail: rossv@unimelb.edu.au;

bozis@unimelb.edu.au

${ }^{\dagger}$ Ross Vlahos and Steven Bozinovski have contributed equally to this work.
Alveolar macrophages (AMs) represent a unique leukocyte population that responds to airborne irritants and microbes. This distinct microenvironment coordinates the maturation of long-lived AMs, which originate from fetal blood monocytes and self-renew through mechanisms dependent on GM-CSF and CSF-1 signaling. Peripheral blood monocytes can also replenish lung macrophages; however, this appears to occur in a stimuli specific manner. In addition to mounting an appropriate immune response during infection and injury, AMs actively coordinate the resolution of inflammation through efferocytosis of apoptotic cells. Any perturbation of this process can lead to deleterious responses. In chronic obstructive pulmonary disease (COPD), there is an accumulation of airway macrophages that do not conform to the classic M1/M2 dichotomy. There is also a skewed transcriptome profile that favors expression of wound-healing M2 markers, which is reflective of a deficiency to resolve inflammation. Endogenous mediators that can promote an imbalance in inhibitory M1 vs. healing M2 macrophages are discussed, as they are the plausible mechanisms underlying why AMs fail to effectively resolve inflammation and restore normal lung homeostasis in COPD.

Keywords: alveolar macrophage, chronic obstructive pulmonary disease, efferocytosis, lung inflammation, oxidative stress, resolution

\section{INTRODUCTION}

Macrophages are essential for pulmonary host defense through their capacity to survey the exposed airways and regulate innate and adaptive immunity. The pulmonary macrophage system consists of several different populations that are found in anatomically distinct compartments, including the airways, alveolar spaces [alveolar macrophages (AMs)], and resident lung tissue. AMs constitute over $90 \%$ of the pulmonary macrophage population (1) and have traditionally thought to originate from the bone marrow (2). More recently, it has been shown that although AMs originate from fetal blood monocytes within the first week of life via GM-CSF dependent mechanisms, maintenance of this population during homeostasis is dependent on their self-renewing capacity (3). Once, developed, this lung macrophage pool is longlived in humans (2) in the absence of an inflammatory insult. This finding has been replicated in mice, where there was approximately $40 \%$ turnover of AMs over 1 year in the absence of an insult (4). Hence, the macrophage lung population, particularly during the steady state, is primarily sustained by the self-renewal of pulmonary AMs through local proliferation (5). The local proliferation of AMs during homeostatic repletion is dependent on both GM-CSF and CSF-1, with no dependence on IL-4 signaling (6). Both GM-CSF and M-CSF also control the proliferation and survival of AMs (7). The differentiation of AMs is particularly dependent on GM-CSF, where the leukocyte growth factor regulates essential functions including phagocytosis and surfactant catabolism through the PU.1 transcription factor (8). This is consistent with a unique airway environment that is associated with high oxygen tension and high levels of GM-CSF.
Resident AMs are constantly encountering inhaled substances due to their exposed position in the alveolar lumen. AMs are considered to be major effector cells in innate host defense against inhaled irritants by virtue of their phagocytic ability (9). Therefore, it is vital that resident AMs are kept in a relatively quiescent state with active suppression of inflammation in response to harmless antigens to prevent collateral damage to lung tissue (10). Although AM exhibit microbicidal, tumoricidal, and parasiticidal activities $(9,11)$, they are functionally less responsive than tissue-resident macrophages. Relative to tissue macrophages, they display reduced phagocytic capacity, reduced respiratory burst, and a diminished capacity to present antigen to T cells (12-14). Under homeostatic conditions, AMs are closely associated with alveolar epithelial cells (AECs), and this in turn induces the expression of epithelial restricted $\alpha v \beta 6$ integrin that binds and activates latent TGF $\beta$ (15). TGF $\beta$ can inhibit macrophage activation that is implicated in alveolar wall destruction (15). Upon recognition of antigens by TLRs, the rapid induction of actin polymerization promotes AMs detachment from AECs (16). The subsequent production of proteases by activated AMs then activates latent TGF $\beta$, thereby reinstating AMs to their resting state (16). This illustrates an intricate mechanism of microenvironmental macrophage specialization to keep the macrophage response in check. AMs can also produce TGF $\beta$, which suppresses T cell activation and has been shown to promote the emergence of $\mathrm{T}$ regulatory cells (17).

\section{ROLE OF AMs IN INNATE HOST DEFENSE}

In contrast to the self-renewing capacity of AMs during the steady state, inflammatory and infective insults dramatically change the 
dynamics of local lung macrophages. Using chimeric mice, parabiosis, and adoptive cellular transfer models, it has been established that bone marrow-derived blood monocytes replenish the AM pool during lethal irradiation (3). This is context specific, as inoculation with influenza in mice, which dramatically depletes resident AMs in a strain specific manner, led to restoration of this population through self-renewal proliferative mechanisms (6). This infectious model also promotes the substantial recruitment of blood monocytes; however, the fate of monocyte-derived macrophages has yet to be established in this setting. Using a similar approach, LPS has been shown to restore lung macrophage numbers through both local proliferation of resident macrophages and maturation of recruited blood monocytes (18). Mouse blood monocytes can be subdivided according to differential expression of chemokine receptors and adhesion molecules that are involved in cell recruitment. $\mathrm{CCR}^{2+} \mathrm{Gr}^{\mathrm{hi}} \mathrm{CX}_{3} \mathrm{CR} 1^{\text {lo }}$ is actively recruited to inflamed tissues by virtue of their recognition of CCL2 (also known as MCP1) (19). Mouse monocytes that are $\mathrm{CCR}^{2+} \mathrm{Gr}^{\mathrm{hi}} \mathrm{CX}_{3} \mathrm{CR} 1^{\text {lo }}$ are classified as pro-inflammatory but share morphological characteristic and chemokine receptor patterns with the classical human monocytes (CD14 ${ }^{\text {hi }} \mathrm{CD} 16^{-} \mathrm{CX}_{3} \mathrm{CR} 1^{\mathrm{lo}}$ ) (19). Monocyte-derived macrophages can acquire distinct morphological and functional properties as directed by the immunological microenvironment.

Alveolar macrophages coordinate antimicrobial defenses through expression of receptors for immunoglobulin $\left(F_{c} R\right)$, complement, $\beta$-glucan, mannose, and several types of scavenger receptors that together facilitates phagocytosis (20). AMs generate reactive nitrogen and oxygen intermediates involved in macrophagemediated defense against microbial infection $(21,22)$. Surfactant protein A augments pathogen killing by AMs by stimulating phagocytosis and production of reactive oxygen-nitrogen intermediates (23). In addition, AMs can initiate recruitment of inflammatory cells from pulmonary vasculature into the alveolar space. There are a number of studies that implicate AMs as central effector cells in the production of pro-inflammatory cytokines, which initiate the early phase of neutrophil influx in response to acute lung injury caused by bacterial products $(24,25)$. More recently, selective targeting strategies that ablate different monocyte/macrophage populations have identified an important role for peripheral blood monocytes. Ablation of CCR2 ${ }^{\text {hi }}$ monocytes significantly reduced indices of acute lung injury (26). It is plausible that AMs may actually play a role in limiting neutrophil influx by controlling MCP-1 production through AECs (27). Furthermore, in a murine model of pneumococcal pneumonia, AMs depletion resulted in a failure to modulate the inflammatory response with increased levels of pro-inflammatory cytokines (28). AMs are also central regulators of the resolution of inflammation through their ability to engulf apoptotic neutrophils during the resolution phase $(28,29)$. The active phagocytosis of dying cells by macrophages may also lead to the induction of anti-inflammatory or suppressive properties in macrophages as shown by the inhibition of IL- $1 \beta, \mathrm{IL}-8, \mathrm{TNF} \alpha$, and GM-CSF production (30).

Alveolar macrophages are also indispensable for the clearance of influenza infection in a viral strain-dependent manner in mice. Here, it was established that the depletion of airway macrophages was associated with more severe lung injury following inoculation with BJx109, which is a viral strain that infects macrophages with high efficiency (31). This is in contrast to the highly virulent PR8 strain that poorly replicated in airway macrophages, suggesting that avoidance of AM engagement may contribute to the virulence of influenza strains (31). There is also the important clinical complication of secondary bacterial infections following a significant viral event, where AM function is likely to be compromised. In murine models of secondary bacterial infection, the initial depletion of AMs as a consequence of influenza infection rendered the host susceptible to Streptococcus pneumonia (Spn) colonization and systemic invasion (32). The repletion of resident AMs occurred 2 weeks after influenza, which resulted in the reestablishment of early innate host protection to Spn (32). This AM replenishment phase may represent a window of opportunity for opportunistic respiratory pathogens such as Spn that take advantage of this immunocompromised state. Interferon- $\gamma$ production during the recovery phase of a viral infection can also inhibit lung anti-bacterial defenses. Mechanistically, it was shown that viral-induced production of inteferon- $\gamma$ caused downregulation of the scavenger receptor MARCO, and neutralization of interferon- $\gamma$ prevented secondary pneumococcal infection (33). Using MARCO-deficient mice, it has been established that expression of this scavenger receptor on AMs is critical for efficient clearance of Spn from the lungs (34).

\section{ROLE OF AMS IN CHRONIC OBSTRUCTIVE PULMONARY DISEASE}

There is a large body of evidence implicating AMs in the pathogenesis of Chronic Obstructive Pulmonary Disease (COPD). COPD is a major global health problem and has been predicted to become the third largest cause of death in the world by 2020 (35). Cigarette smoking is the major cause of COPD and accounts for more than $95 \%$ of cases in industrialized countries (36), but other environmental pollutants are important causes in developing countries (37). COPD is "a disease state characterized by airflow limitation that is not fully reversible." The airflow limitation is usually progressive and associated with an abnormal inflammatory response of lungs to noxious particles and gases (38). COPD encompasses chronic obstructive bronchiolitis with fibrosis and obstruction of small airways and emphysema with enlargement of airspaces and destruction of lung parenchyma, loss of lung elasticity, and closure of small airways. Most patients with COPD have all three pathologic conditions (chronic obstructive bronchiolitis, emphysema, and mucus plugging), but the relative extent of emphysema and obstructive bronchiolitis within individual patients can vary.

Studies have highlighted that macrophages play a pivotal role in the pathophysiology of COPD (39). There is a marked increase (5- to 10-fold) in the numbers of macrophages in airways, lung parenchyma, bronchoalveolar lavage fluid (BALF), and sputum in patients with COPD $(40,41)$. A morphometric analysis of macrophage numbers in the parenchyma of patients with emphysema showed a 25-fold increase in the numbers of macrophages in the tissue and alveolar space compared to smokers with normal lung function (42). There is a positive correlation between macrophage numbers in the airways and the severity of COPD (43). In addition, a pathological role for macrophages has been demonstrated, as the depletion of lung macrophages conferred 
protection against the development of emphysema in an experimental model of COPD (44). Macrophages are activated by cigarette smoke and other irritants to release inflammatory mediators. AMs also secrete elastolytic enzymes (proteases), including matrix metalloprotease (MMP)-2, MMP-9, MMP-12, cathepsin K, $\mathrm{L}$, and $\mathrm{S}$ in response to irritants and infection, which together are responsible for destruction of lung parenchyma (36). In patients with emphysema, there is an increase in BALF concentrations and macrophage expression of MMP-1 and MMP-9 (45). There is an increase in activity of MMP-9 in the lung parenchyma of patients with emphysema (46). AMs from smokers with normal lung function express more MMP-9 than those from non-smoking healthy subjects (47), and there is an even greater increase in cells from patients with COPD, which have enhanced elastolytic activity (48).

Chronic obstructive pulmonary disease subjects can also be very susceptible to bacterial colonization $(49,50)$ and exacerbations that are commonly caused by respiratory infections of viral and/or bacterial etiology (51). The frequent exacerbator phenotype has been reported, which is associated with a poorer quality of life and increased systemic inflammation (52). Impaired AM function is central to high colonization rates and increased susceptibility to exacerbations observed in COPD. Chronic cigarette smoke exposure is a major cause of COPD, which markedly depletes intracellular GSH stores $(53,54)$. Oxidative stress leads to disruption of GSH metabolism, which is considered as a key susceptibility feature of lung diseases (55). Excessive oxidative stress is particularly deleterious to AM function, leading to a deficiency in phagocytosis of bacteria (56) and efferocytosis of apoptotic cells (57). Treatment with anti-oxidants such as procysteine can significantly improve efferocytic function of AMs isolated from experimental models of COPD (58). Impaired AM-mediated efferocytosis in COPD can be particularly damaging in COPD as neutrophils are persistently recruited into the airways. Cigarette smoke impairs clearance of apoptotic cells through oxidant-dependent activation of RhoA (59) and inhibition of Racl (60), leading to defective actin polymerization normally required for efficient efferocytosis. The inability to efficiently remove exhausted neutrophils has damaging implications in COPD as accumulation of necrotic neutrophils can lead to the indiscriminate release of granule protease pools including neutrophil elastase. Neutrophil elastase localizes to lung elastic fibers in emphysematic patients and degrades extracellular matrix components (61) and can promote the release of mucins through epidermal growth factor receptor (EGFR)-dependent mechanisms (62). EGFR transactivation can also augment inflammatory responses initiated by rhinovirus infection (63). Reactive free radicals also impair clearance mechanisms by directly causing cytoskeletal instability and carbonyl modification of pseudopodia (64-66). Macrophages also interact with carbonyl-adduct modified extracellular matrix proteins, which impair their ability to clear apoptotic neutrophils (67).

In addition to oxidative post translational modification of the host phagocytic machinery, the complex milieu within COPD airways can alter the phenotype of highly plastic airway macrophages. It is becoming increasing clear that different macrophage subpopulations exist in the inflamed lung. Although the existence of such populations is implicated in COPD, the importance of these subpopulations is unknown (68). The ongoing characterization of disease-associated macrophages clearly demonstrates that they do not conform into the classic M1/M2 dichotomy and it is likely that the inflammatory environment of the COPD airways drives development of both M1 and M2 macrophages $(58,69)$. Indeed, it has been shown that iNOS and arginase activity are concurrently elevated in COPD airways. Specifically, elevated iNOS expression has been observed in AMs of COPD patients, which increased with severity of disease and during exacerbations (70-72). Of interest, levels of exhaled nitric oxide (NO) are not elevated in stable COPD, which may be consequential to increased production of superoxide that reacts with $\mathrm{NO}$ to generate the highly reactive nitrogen species, peroxynitrite (73). In addition, arginase- 1 is increased in cigarette smoke exposure models (74), which will reduce Larginine availability to iNOS. Reduced L-arginine bioavailability also stimulates iNOS to simultaneously produce NO and superoxide, which facilitates rapid formation of peroxynitrite (73). Consistent with the concurrent existence of iNOS and arginase expressing macrophages in COPD, nitrotyrosine (product of peroxynitrite) levels have been shown to be increased in sputum macrophages of COPD patients, which are negatively correlated with their lung function (75). Hence, the relative ratio of iNOS expressing M1 macrophages and arginase expressing M2 macrophages will be particularly important to the oxidative/nitrosative state of the lung.

The relative balance between these polarization states can in turn, have a profound impact on disease progression [reviewed in Ref. (76)]. There is evidence for the reprograming of AMs as a consequence of chronic smoke exposure that is associated with the induction of a unique set of genes including MMP12 (77). There is also evidence for the transcriptional skewing of AMs toward an M2 gene profile in smokers with normal lung function that was more evident in smokers who had progressed to develop COPD (78). In this study, they also demonstrate the progressive downregulation of M1 genes (78), which would appear paradoxical to the observation of increased expression of pro-inflammatory mediators in COPD. Hence, there is a need to better define the relative contribution of M1 vs. M2 macrophages as there is emerging evidence that both populations do concurrently exist in COPD airways. Another important consideration in COPD is the interaction between macrophages and $\mathrm{T}$ cell subsets. Although it has been broadly stated that $\mathrm{T}$ cells control the polarization state of macrophages, macrophages can also potently regulate $\mathrm{T}$ cell biology $(79,80)$. Since $\mathrm{T}$ cell subsets including $\mathrm{CD} 8^{+} \mathrm{T}$ cells, $\mathrm{T}_{\mathrm{H}} 17$, and iBALT formation are implicated in COPD pathology, the role of macrophages in regulating $\mathrm{T}$ cell biology remains to be elucidated.

The accumulation of M2 skewed airway macrophages may be reflective of deficient resolution processes that normally switch off inflammation and restore lung homeostasis. Since the stimulation of non-phlogistic phagocytosis is essential to resolution of inflammation, the oxidant-dependent impairment of efferocytic clearance of damaged tissue may maintain M2 macrophages in COPD. The induction of CD163 is commonly recognized as a marker for M2-alternatively activated macrophages involved in wound-healing $(81,82)$ and CD163 positive macrophages are 
highly prominent in the BAL compartment of current and exsmokers with COPD (83). CD163 may constitute a major defense mechanism to protect the lung as it functions as a scavenger receptor, which promotes degradation of $\mathrm{HbHp}$ complexes and signaling that induces expression of heme-oxygenase-1 (HO-1) (82). The persistence of HO-1 in COPD airways (84) is consistent with an environment where there is excessive oxidative stress and a deficiency in the resolution of inflammation. The mediators that induce expression of M2 markers in COPD have not been comprehensively characterized. Interleukin-10 (IL-10) is a potent inducer of CD163 expression in human monocytes (85); however, there is some data to suggest that the level of IL-10 positive macrophages is reduced in COPD (86). An alternate mediator that has been shown to potently induce expression of CD163 in human monocyte-derived macrophages is serum amyloid A (SAA) (87). SAA is a major acute phase reactant that has now been shown to be expressed in COPD lungs, where its levels correlated with neutrophilic inflammation (88). SAA is known to target the ALX/FPR2 receptor and oppose the actions of pro-resolving ligands such as LipoxinA 4 (88-90), which normally stimulate non-phlogistic clearance pathways. In addition to CD163, SAA can also stimulate the expression of the $\mathrm{T}_{\mathrm{H}} 17$ polarizing cytokines, IL-6, and IL-1 $\beta$ in monocyte-derived macrophages, and neutralization of IL-17A expression suppressed neutrophil airway inflammation stimulated by SAA (91). Hence, the persistence of host defense mediators such as SAA may maintain alternative macrophage populations in COPD airways that not only express M2 markers of wound repair, but also markers of acute inflammation.

\section{CONCLUSION}

In this review, the origin and maintenance of AMs and their essential role in innate immunity to respiratory pathogens are discussed. There is emerging evidence for the self-renewal of AMs and lung tissue macrophages through mechanisms dependent on GM-CSF and CSF-1 signaling. The role of peripheral monocytes in replenishing lung macrophages appear to be context specific, as radiation-induced lung injury stimulates monocytic replenishment, whereas influenza infection replenishes AMs through local proliferation of resident macrophages. In diseases such as COPD where there is an accumulation of airway macrophages, the relative contribution of monocyte versus local proliferation of mature AM populations remains to be determined. Lineage tracing of monocytes/macrophages in experimental models of COPD will inform on the origin of macrophages associated with disease pathology.

Alveolar macrophages coordinate the efficient clearance of inhaled irritants and microbes to resolve inflammation. In addition, AMs display efferocytic activity to clear damaged tissue and cells following injury and infection. In COPD, the persistence of inflammation and the inability to efficiently clear damaged tissue and exhausted immune cells such as neutrophils may be due to excessive oxidative stress that impairs the phagocytic capacity of AMs. Airway macrophages in COPD also display a unique phenotype that is associated with the induction of M2-related genes, which are likely to be upregulated in response to local tissue damage (Figure 1). The maintenance of this subpopulation may also contribute to deleterious remodeling in COPD. Thus, there is a

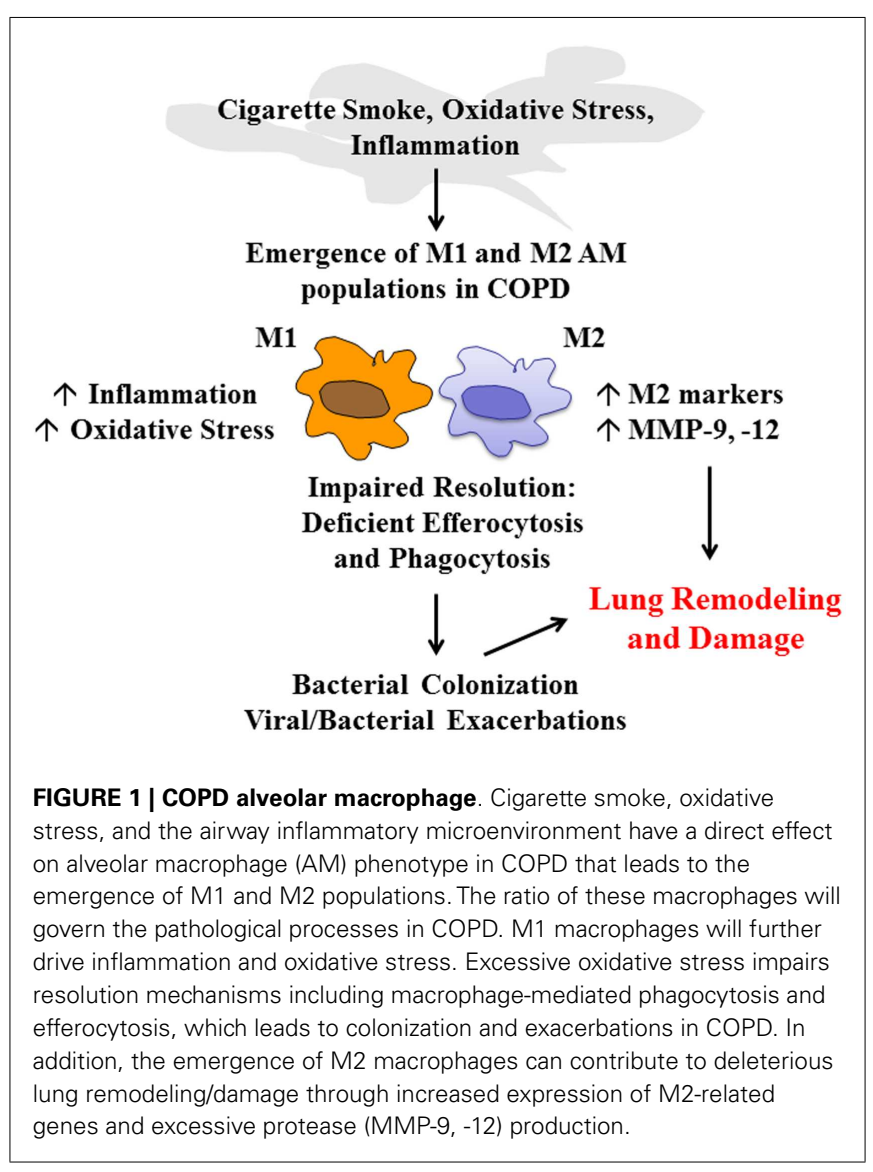

need to better characterize distinct AM populations present in COPD and their relative contribution to disease pathology, as their highly plastic nature offer a therapeutic opportunity to reprogram macrophages to facilitate restoration of lung homeostasis.

\section{REFERENCES}

1. van oud Alblas AB, van Furth R. Origin, kinetics, and characteristics of pulmonary macrophages in the normal steady state. J Exp Med (1979) 149(6):1504-18. doi:10.1084/jem.149.6.1504

2. Thomas ED, Ramberg RE, Sale GE, Sparkes RS, Golde DW. Direct evidence for a bone marrow origin of the alveolar macrophage in man. Science (1976) 192(4243):1016-8. doi:10.1126/science.775638

3. Guilliams M, De Kleer I, Henri S, Post S, Vanhoutte L, De Prijck S, et al. Alveolar macrophages develop from fetal monocytes that differentiate into long-lived cells in the first week of life via GM-CSF. J Exp Med (2013) 210(10):1977-92. doi:10.1084/jem.20131199

4. Maus UA, Janzen S, Wall G, Srivastava M, Blackwell TS, Christman JW, et al. Resident alveolar macrophages are replaced by recruited monocytes in response to endotoxin-induced lung inflammation. Am J Respir Cell Mol Biol (2006) 35(2):227-35. doi:10.1165/rcmb.2005-0241OC

5. Tarling JD, Lin HS, Hsu S. Self-renewal of pulmonary alveolar macrophages: evidence from radiation chimera studies. J Leukoc Biol (1987) 42(5):443-6.

6. Hashimoto D, Chow A, Noizat C, Teo P, Beasley MB, Leboeuf M, et al. Tissueresident macrophages self-maintain locally throughout adult life with minimal contribution from circulating monocytes. Immunity (2013) 38(4):792-804. doi:10.1016/j.immuni.2013.04.004

7. Lin HS, Lokeshwar BL, Hsu S. Both granulocyte-macrophage CSF and macrophage CSF control the proliferation and survival of the same subset of alveolar macrophages. J Immunol (1989) 142(2):515-9. 
8. Shibata Y, Berclaz PY, Chroneos ZC, Yoshida M, Whitsett JA, Trapnell BC. GM-CSF regulates alveolar macrophage differentiation and innate immunity in the lung through PU.1. Immunity (2001) 15(4):557-67. doi:10.1016/S10747613(01)00218-7

9. Franke-Ullmann G, Pfortner C, Walter P, Steinmuller C, Lohmann-Matthes ML, Kobzik L. Characterization of murine lung interstitial macrophages in comparison with alveolar macrophages in vitro. J Immunol (1996) 157(7):3097-104.

10. Thepen T, Van Rooijen N, Kraal G. Alveolar macrophage elimination in vivo is associated with an increase in pulmonary immune response in mice. J Exp Med (1989) 170(2):499-509. doi:10.1084/jem.170.2.499

11. Prokhorova S, Lavnikova N, Laskin DL. Functional characterization of interstitial macrophages and subpopulations of alveolar macrophages from rat lung. J Leukoc Biol (1994) 55(2):141-6.

12. Holt PG. Inhibitory activity of unstimulated alveolar macrophages on $\mathrm{T}$ lymphocyte blastogenic response. Am Rev Respir Dis (1978) 118(4):791-3.

13. Hoidal JR, Schmeling D, Peterson PK. Phagocytosis, bacterial killing, and metabolism by purified human lung phagocytes. J Infect Dis (1981) 144(1):61-71. doi:10.1093/infdis/144.1.61

14. Blumenthal RL, Campbell DE, Hwang P, DeKruyff RH, Frankel LR, Umetsu DT. Human alveolar macrophages induce functional inactivation in antigenspecific CD4 T cells. JAllergy Clin Immunol (2001) 107(2):258-64. doi:10.1067/ mai.2001.112845

15. Morris DG, Huang X, Kaminski N, Wang Y, Shapiro SD, Dolganov G, et al. Loss of integrin alpha(v)beta6-mediated TGF-beta activation causes Mmp12-dependent emphysema. Nature (2003) 422(6928):169-73. doi:10.1038/ nature 01413

16. Takabayshi K, Corr M, Hayashi T, Redecke V, Beck L, Guiney D, et al. Induction of a homeostatic circuit in lung tissue by microbial compounds. Immunity (2006) 24(4):475-87. doi:10.1016/j.immuni.2006.02.008

17. Coleman MM, Ruane D, Moran B, Dunne PJ, Keane J, Mills KH. Alveolar macrophages contribute to respiratory tolerance by inducing FoxP3 expression in naive T cells. Am J Respir Cell Mol Biol (2013) 48(6):773-80. doi:10.1165/ rcmb.2012-0263OC

18. Duan M, Li WC, Vlahos R, Maxwell MJ, Anderson GP, Hibbs ML. Distinct macrophage subpopulations characterize acute infection and chronic inflammatory lung disease. J Immunol (2012) 189(2):946-55. doi:10.4049/jimmunol. 1200660

19. Geissmann F, Jung S, Littman DR. Blood monocytes consist of two principal subsets with distinct migratory properties. Immunity (2003) 19(1):71-82. doi:10.1016/S1074-7613(03)00174-2

20. Taylor PR, Martinez-Pomares L, Stacey M, Lin HH, Brown GD, Gordon S. Macrophage receptors and immune recognition. Annu Rev Immunol (2005) 23:901-44. doi:10.1146/annurev.immunol.23.021704.115816

21. Nathan CF, Hibbs JB Jr. Role of nitric oxide synthesis in macrophage antimicrobial activity. Curr Opin Immunol (1991) 3(1):65-70. doi:10.1016/0952-7915(91) 90079-G

22. Fantone JC, Ward PA. Role of oxygen-derived free radicals and metabolites in leukocyte-dependent inflammatory reactions. Am J Pathol (1982) 107(3):395-418.

23. Hickman-Davis JM, O’Reilly P, Davis IC, Peti-Peterdi J, Davis G, Young KR, et al. Killing of Klebsiella pneumoniae by human alveolar macrophages. Am J Physiol Lung Cell Mol Physiol (2002) 282:L944-56. doi:10.1152/ajplung.00216.2001

24. Hashimoto S, Pittet JF, Hong K, Folkesson H, Bagby G, Kobzik L, et al. Depletion of alveolar macrophages decreases neutrophil chemotaxis to Pseudomonas airspace infections. Am J Physiol (1996) 270(5 Pt 1):L819-28.

25. Maus UA, Koay MA, Delbeck T, Mack M, Ermert M, Ermert L, et al. Role of resident alveolar macrophages in leukocyte traffic into the alveolar air space of intact mice. Am J Physiol Lung Cell Mol Physiol (2002) 282(6):L1245-52. doi:10.1152/ajplung.00453.2001

26. Dhaliwal K, Scholefield E, Ferenbach D, Gibbons M, Duffin R, Dorward DA, et al. Monocytes control second-phase neutrophil emigration in established lipopolysaccharide-induced murine lung injury. Am J Respir Crit Care Med (2012) 186(6):514-24. doi:10.1164/rccm.201112-2132OC

27. Beck-Schimmer B, Schwendener R, Pasch T, Reyes L, Booy C, Schimmer RC. Alveolar macrophages regulate neutrophil recruitment in endotoxin-induced lung injury. Respir Res (2005) 6:61. doi:10.1186/1465-9921-6-61
28. Knapp S, Leemans JC, Florquin S, Branger J, Maris NA, Pater J, et al. Alveolar macrophages have a protective antiinflammatory role during murine pneumococcal pneumonia. Am J Respir Crit Care Med (2003) 167(2):171-9. doi:10.1164/rccm.200207-698OC

29. Cox G, Crossley J, Xing Z. Macrophage engulfment of apoptotic neutrophils contributes to the resolution of acute pulmonary inflammation in vivo. Am J Respir Cell Mol Biol (1995) 12(2):232-7. doi:10.1165/ajrcmb.12.2. 7865221

30. Fadok VA, Bratton DL, Konowal A, Freed PW, Westcott JY, Henson PM Macrophages that have ingested apoptotic cells in vitro inhibit proinflammatory cytokine production through autocrine/paracrine mechanisms involving TGF-beta, PGE2, and PAF. J Clin Invest (1998) 101(4):890-8. doi:10.1172/ JCI1112

31. Tate MD, Pickett DL, van Rooijen N, Brooks AG, Reading PC. Critical role of airway macrophages in modulating disease severity during influenza virus infection of mice. J Virol (2010) 84(15):7569-80. doi:10.1128/JVI.00291-10

32. Ghoneim HE, Thomas PG, McCullers JA. Depletion of alveolar macrophages during influenza infection facilitates bacterial superinfections. J Immunol (2013) 191(3):1250-9. doi:10.4049/jimmunol.1300014

33. Sun K, Metzger DW. Inhibition of pulmonary antibacterial defense by interferon-gamma during recovery from influenza infection. Nat Med (2008) 14(5):558-64. doi:10.1038/nm1765

34. Arredouani M, Yang Z, Ning Y, Qin G, Soininen R, Tryggvason K, et al. The scavenger receptor MARCO is required for lung defense against pneumococcal pneumonia and inhaled particles. J Exp Med (2004) 200(2):267-72. doi:10.1084/jem.20040731

35. Lopez AD, Murray CC. The global burden of disease, 1990-2020. Nat Med (1998) 4(11):1241-3. doi:10.1038/3218

36. Barnes PJ, Shapiro SD, Pauwels RA. Chronic obstructive pulmonary disease: molecular and cellular mechanisms. Eur Respir J (2003) 22(4):672-88. doi:10.1183/09031936.03.00040703

37. Dennis RJ, Maldonado D, Norman S, Baena E, Martinez G. Woodsmoke exposure and risk for obstructive airways disease among women. Chest (1996) 109(1):115-9. doi:10.1378/chest.109.1.115

38. Pauwels RA, Buist AS, Calverley PM, Jenkins CR, Hurd SS, Committee GS. Global strategy for the diagnosis, management, and prevention of chronic obstructive pulmonary disease. NHLBI/WHO global initiative for chronic obstructive lung disease (GOLD) workshop summary. Am J Respir Crit Care Med (2001) 163(5):1256-76. doi:10.1164/ajrccm.163.5.2101039

39. Shapiro SD. The macrophage in chronic obstructive pulmonary disease. Am J Respir Crit Care Med (1999) 160(5 Pt 2):S29-32. doi:10.1164/ajrccm.160. supplement_1.9

40. Pesci A, Balbi B, Majori M, Cacciani G, Bertacco S, Alciato P, et al. Inflammatory cells and mediators in bronchial lavage of patients with chronic obstructive pulmonary disease. Eur Respir J (1998) 12(2):380-6. doi:10.1183/09031936.98. 12020380

41. Keatings VM, Collins PD, Scott DM, Barnes PJ. Differences in interleukin-8 and tumor necrosis factor-alpha in induced sputum from patients with chronic obstructive pulmonary disease or asthma. Am J Respir Crit Care Med (1996) 153(2):530-4. doi:10.1164/ajrccm.153.2.8564092

42. Retamales I, Elliott WM, Meshi B, Coxson HO, Pare PD, Sciurba FC, et al. Amplification of inflammation in emphysema and its association with latent adenoviral infection. Am J Respir Crit Care Med (2001) 164(3):469-73. doi:10.1164/ ajrccm.164.3.2007149

43. Di Stefano A, Capelli A, Lusuardi M, Balbo P, Vecchio C, Maestrelli P, et al. Severity of airflow limitation is associated with severity of airway inflammation in smokers. Am J Respir Crit Care Med (1998) 158(4):1277-85. doi:10.1164/ajrccm. 158.4.9802078

44. Beckett EL, Stevens RL, Jarnicki AG, Kim RY, Hanish I, Hansbro NG, et al. A new short-term mouse model of chronic obstructive pulmonary disease identifies a role for mast cell tryptase in pathogenesis. J Allergy Clin Immunol (2013) 131(3):752-62. doi:10.1016/j.jaci.2012.11.053

45. Finlay GA, O’Driscoll LR, Russell KJ, D’Arcy EM, Masterson JB, FitzGerald MX, et al. Matrix metalloproteinase expression and production by alveolar macrophages in emphysema. Am J Respir Crit Care Med (1997) 156(1):240-7. doi:10.1164/ajrccm.156.1.9612018 
46. Ohnishi K, Takagi M, Kurokawa Y, Satomi S, Konttinen YT. Matrix metalloproteinase-mediated extracellular matrix protein degradation in human pulmonary emphysema. Lab Invets (1998) 78(9):1077-87.

47. Lim S, Roche N, Oliver BG, Mattos W, Barnes PJ, Chung KF. Balance of matrix metalloprotease- 9 and tissue inhibitor of metalloprotease- 1 from alveolar macrophages in cigarette smokers. Regulation by interleukin-10. Am J Respir Crit Care Med (2000) 162(4 Pt 1):1355-60. doi:10.1164/ajrccm. 162.4.9910097

48. Russell RE, Culpitt SV, DeMatos C, Donnelly L, Smith M, Wiggins J, et al. Release and activity of matrix metalloproteinase- 9 and tissue inhibitor of metalloproteinase-1 by alveolar macrophages from patients with chronic obstructive pulmonary disease. Am J Respir Cell Mol Biol (2002) 26(5):602-9. doi:10.1165/ajrcmb.26.5.4685

49. Monso E, Ruiz J, Rosell A, Manterola J, Fiz J, Morera J, et al. Bacterial infection in chronic obstructive pulmonary disease. A study of stable and exacerbated outpatients using the protected specimen brush. Am J Respir Crit Care Med (1995) 152(4 Pt 1):1316-20. doi:10.1164/ajrccm.152.4.7551388

50. Pela R, Marchesani F, Agostinelli C, Staccioli D, Cecarini L, Bassotti C, et al. Airways microbial flora in COPD patients in stable clinical conditions and during exacerbations: a bronchoscopic investigation. Monaldi Arch Chest Dis (1998) 53(3):262-7.

51. Papi A, Bellettato CM, Braccioni F, Romagnoli M, Casolari P, Caramori G, et al. Infections and airway inflammation in chronic obstructive pulmonary disease severe exacerbations. Am J Respir Crit Care Med (2006) 173(10):1114-21. doi:10.1164/rccm.200506-859OC

52. Hurst JR, Vestbo J, Anzueto A, Locantore N, Mullerova H, Tal-Singer R, et al. Susceptibility to exacerbation in chronic obstructive pulmonary disease. $\mathrm{N} \mathrm{Engl}$ J Med (2010) 363(12):1128-38. doi:10.1056/NEJMoa0909883

53. Birrell MA, Wong S, Catley MC, Belvisi MG. Impact of tobacco-smoke on key signaling pathways in the innate immune response in lung macrophages. $J$ Cell Physiol (2008) 214(1):27-37. doi:10.1002/jcp.21158

54. Muller T, Gebel S. The cellular stress response induced by aqueous extracts of cigarette smoke is critically dependent on the intracellular glutathione concentration. Carcinogenesis (1998) 19(5):797-801. doi:10.1093/carcin/19.5.797

55. Rahman I, MacNee W. Oxidative stress and regulation of glutathione in lung inflammation. Eur Respir J (2000) 16(3):534-54. doi:10.1034/j.1399-3003.2000. 016003534.x

56. Marti-Lliteras P, Regueiro V, Morey P, Hood DW, Saus C, Sauleda J, et al. Nontypeable Haemophilus influenzae clearance by alveolar macrophages is impaired by exposure to cigarette smoke. Infect Immun (2009) 77(10):4232-42. doi:10.1128/IAI.00305-09

57. Hodge S, Hodge G, Ahern J, Jersmann H, Holmes M, Reynolds PN. Smoking alters alveolar macrophage recognition and phagocytic ability: implications in chronic obstructive pulmonary disease. Am J Respir Cell Mol Biol (2007) 37(6):748-55. doi:10.1165/rcmb.2007-0025OC

58. Hodge S, Matthews G, Mukaro V, Ahern J, Shivam A, Hodge G, et al. Cigarette smoke-induced changes to alveolar macrophage phenotype and function are improved by treatment with procysteine. Am J Respir Cell Mol Biol (2011) 44(5):673-81. doi:10.1165/rcmb.2009-0459OC

59. Richens TR, Linderman DJ, Horstmann SA, Lambert C, Xiao YQ, Keith RL, et al. Cigarette smoke impairs clearance of apoptotic cells through oxidant-dependent activation of RhoA. Am J Respir Crit Care Med (2009) 179(11):1011-21. doi:10.1164/rccm.200807-1148OC

60. Minemetsu N, Blumental-Perry A, Shapiro SD. Cigarette smoke inhibits engulfment of apoptotic cells by macrophages through inhibition of actin rearrangement. Am J Respir Cell Mol Biol (2011) 44(4):474-82. doi:10.1165/rcmb.20090463OC

61. Damiano VV, Tsang A, Kucich U, Abrams WR, Rosenbloom J, Kimbel P, et al. Immunolocalization of elastase in human emphysematous lungs. J Clin Invest (1986) 78(2):482-93. doi:10.1172/JCI112600

62. Shao MX, Nadel JA. Neutrophil elastase induces MUC5AC mucin production in human airway epithelial cells via a cascade involving protein kinase C, reactive oxygen species, and TNF-alpha-converting enzyme. J Immunol (2005) 175(6):4009-16. doi:10.4049/jimmunol.175.6.4009

63. Liu K, Gualano RC, Hibbs ML, Anderson GP, Bozinovski S. Epidermal growth factor receptor signaling to Erk1/2 and STATs control the intensity of the epithelial inflammatory responses to rhinovirus infection. J Biol Chem (2008) 283(15):9977-85. doi:10.1074/jbc.M710257200
64. Banan A, Zhang Y, Losurdo J, Keshavarzian A. Carbonylation and disassembly of the F-actin cytoskeleton in oxidant induced barrier dysfunction and its prevention by epidermal growth factor and transforming growth factor alpha in a human colonic cell line. Gut (2000) 46(6):830-7. doi:10.1136/gut.46.6.830

65. Smerjac SM, Bizzozero OA. Cytoskeletal protein carbonylation and degradation in experimental autoimmune encephalomyelitis. J Neurochem (2008) 105(3):763-72. doi:10.1111/j.1471-4159.2007.05178.x

66. Bozinovski S, Vlahos R, Zhang Y, Lah LC, Seow HJ, Mansell A, et al. Carbonylation caused by cigarette smoke extract is associated with defective macrophage immunity. Am J Respir Cell Mol Biol (2011) 45(2):229-36. doi:10.1165/rcmb. 2010-0272OC

67. Kirkham PA, Spooner G, Rahman I, Rossi AG. Macrophage phagocytosis of apoptotic neutrophils is compromised by matrix proteins modified by cigarette smoke and lipid peroxidation products. Biochem Biophys Res Commun (2004) 318(1):32-7. doi:10.1016/j.bbrc.2004.04.003

68. Barnes PJ. Alveolar macrophages as orchestrators of COPD. COPD (2004) 1(1):59-70. doi:10.1081/COPD- 120028701

69. Mosser DM, Edwards JP. Exploring the full spectrum of macrophage activation. Nat Rev Immunol (2008) 8(12):958-69. doi:10.1038/nri2448

70. Agusti AG, Villaverde JM, Togores B, Bosch M. Serial measurements of exhaled nitric oxide during exacerbations of chronic obstructive pulmonary disease. Eur Respir J (1999) 14(3):523-8. doi:10.1034/j.1399-3003.1999.14d34.x

71. Bhowmik A, Seemungal TA, Donaldson GC, Wedzicha JA. Effects of exacerbations and seasonality on exhaled nitric oxide in COPD. Eur Respir J (2005) 26(6):1009-15. doi:10.1183/09031936.05.00047305

72. Maziak W, Loukides S, Culpitt S, Sullivan P, Kharitonov SA, Barnes PJ. Exhaled nitric oxide in chronic obstructive pulmonary disease. Am J Respir Crit Care Med (1998) 157(3 Pt 1):998-1002. doi:10.1164/ajrccm.157.3.97-05009

73. Maarsingh H, Pera T, Meurs H. Arginase and pulmonary diseases. Naunyn Schmiedebergs Arch Pharmacol (2008) 378(2):171-84. doi:10.1007/s00210-0080286-7

74. Gebel S, Gerstmayer B, Kuhl P, Borlak J, Meurrens K, Muller T. The kinetics of transcriptomic changes induced by cigarette smoke in rat lungs reveals a specific program of defense, inflammation, and circadian clock gene expression. Toxicol Sci (2006) 93(2):422-31. doi:10.1093/toxsci/kfl071

75. Ichinose M, Sugiura H, Yamagata S, Koarai A, Shirato K. Increase in reactive nitrogen species production in chronic obstructive pulmonary disease airways. Am J Respir Crit Care Med (2000) 162(2 Pt 1):701-6. doi:10.1164/ajrccm.162.2. 9908132

76. Mills CD, Ley K. M1 and M2 macrophages: the chicken and the egg of immunity. J Innate Immun (2014) 6(6). doi:10.1159/000364945

77. Woodruff PG, Koth LL, Yang YH, Rodriguez MW, Favoreto S, Dolganov GM, et al. A distinctive alveolar macrophage activation state induced by cigarette smoking. Am J Respir Crit Care Med (2005) 172(11):1383-92. doi:10.1164/rccm. 200505-686OC

78. Shaykhiev R, Krause A, Salit J, Strulovici-Barel Y, Harvey BG, O’Connor TP, et al. Smoking-dependent reprogramming of alveolar macrophage polarization: implication for pathogenesis of chronic obstructive pulmonary disease. J Immunol (2009) 183(4):2867-83. doi:10.4049/jimmunol.0900473

79. Mills CD, Kincaid K, Alt JM, Heilman MJ, Hill AM. M-1/M-2 macrophages and the Th1/Th2 paradigm. J Immunol (2000) 164(12):6166-73. doi:10.4049/ jimmunol.164.12.6166

80. Mills CD. M1 and M2 macrophages: oracles of health and disease. Crit Rev Immunol (2012) 32(6):463-88. doi:10.1615/CritRevImmunol.v32.i6.10

81. Mantovani A, Sica A, Sozzani S, Allavena P, Vecchi A, Locati M. The chemokine system in diverse forms of macrophage activation and polarization. Trends Immunol (2004) 25(12):677-86. doi:10.1016/j.it.2004.09.015

82. Van Gorp H, Delputte PL, Nauwynck HJ. Scavenger receptor CD163, a Jackof-all-trades and potential target for cell-directed therapy. Mol Immunol (2010) 47(7-8):1650-60. doi:10.1016/j.molimm.2010.02.008

83. Kunz LI, Lapperre TS, Snoeck-Stroband JB, Budulac SE, Timens W, van Wijngaarden S, et al. Smoking status and anti-inflammatory macrophages in bronchoalveolar lavage and induced sputum in COPD. Respir Res (2011) 12:34 doi:10.1186/1465-9921-12-34

84. Dolinay T, Choi AM, Ryter SW. Heme oxygenase-1/CO as protective mediators in cigarette smoke-induced lung cell injury and chronic obstructive pulmonary disease. Curr Pharm Biotechnol (2012) 13(6):769-76. doi:10.2174/ 138920112800399338 
85. Williams L, Jarai G, Smith A, Finan P. IL-10 expression profiling in human monocytes. J Leukoc Biol (2002) 72(4):800-9.

86. Takanashi S, Hasegawa Y, Kanehira Y, Yamamoto K, Fujimoto K, Satoh K, et al. Interleukin-10 level in sputum is reduced in bronchial asthma, COPD and in smokers. Eur Respir J (1999) 14(2):309-14. doi:10.1183/09031936.99. 14230999

87. Anthony D, McQualter JL, Bishara M, Lim EX, Yatmaz S, Seow HJ, et al. SAA drives proinflammatory heterotypic macrophage differentiation in the lung via CSF-1R-dependent signaling. FASEB J (2014). doi:10.1096/fj.14250332

88. Bozinovski S, Uddin M, Vlahos R, Thompson M, McQualter JL, Merritt AS, et al. Serum amyloid A opposes lipoxin A(4) to mediate glucocorticoid refractory lung inflammation in chronic obstructive pulmonary disease. Proc Natl Acad Sci U S A (2012) 109(3):935-40. doi:10.1073/pnas.1109382109

89. Bozinovski S, Anthony D, Anderson GP, Irving LB, Levy BD, Vlahos R. Treating neutrophilic inflammation in COPD by targeting ALX/FPR2 resolution pathways. Pharmacol Ther (2013) 140(3):280-9. doi:10.1016/j.pharmthera. 2013.07.007

90. El Kebir D, Jozsef L, Khreiss T, Pan W, Petasis NA, Serhan CN, et al. Aspirintriggered lipoxins override the apoptosis-delaying action of serum amyloid A in human neutrophils: a novel mechanism for resolution of inflammation. J Immunol (2007) 179(1):616-22. doi:10.4049/jimmunol.179.1.616
91. Anthony D, Seow HJ, Uddin M, Thompson M, Dousha L, Vlahos R, et al. Serum amyloid A promotes lung neutrophilia by increasing IL-17A levels in the mucosa and gammadelta T cells. Am J Respir Crit Care Med (2013) 188(2):179-86. doi:10.1164/rccm.201211-2139OC

Conflict of Interest Statement: The authors declare that the research was conducted in the absence of any commercial or financial relationships that could be construed as a potential conflict of interest.

Received: 22 July 2014; paper pending published: 18 August 2014; accepted: 26 August 2014; published online: 10 September 2014.

Citation: Vlahos $R$ and Bozinovski $S$ (2014) Role of alveolar macrophages in chronic obstructive pulmonary disease. Front. Immunol. 5:435. doi: 10.3389/fimmu.2014.00435

This article was submitted to Molecular Innate Immunity, a section of the journal Frontiers in Immunology.

Copyright (c) 2014 Vlahos and Bozinovski. This is an open-access article distributed under the terms of the Creative Commons Attribution License (CC BY). The use, distribution or reproduction in other forums is permitted, provided the original author $(s)$ or licensor are credited and that the original publication in this journal is cited, in accordance with accepted academic practice. No use, distribution or reproduction is permitted which does not comply with these terms. 